\section{Genes, patents and insurance}

SIR - The recent Commentary on "The case for genomic patenting" 1 makes three questionable points in attempting to justify the corporate interests of Human Genome Sciences (HGS) and SmithKline Beecham Pharmaceuticals (SKB) with regard to their expressed sequence tag (EST) database, while at the same time criticizing the position of SKB's rival, Merck \& Co.

These points are (1) that ESTs should be patentable, (2) that the HGS conditions for access to its EST database are reasonable and (3) that Merck lacks an "intellectually consistent position" in attempting to create a public domain EST database.

On the first point, the author glosses over compelling arguments, as previously made by others ${ }^{2}$, that ESTs are not patentable because they lack utility. ESTs lack utility for patent purposes when the function and coding sequence of the gene represented by the EST are unknown. The argument that an EST has utility as a diagnostic test is speculative without an actual demonstration of such a test. The policy argument that ESTs should be patentable because publication of an EST prevents a later patent on the entire sequence is not consistent with established legal precedent. In the United States, at least, it is well established $^{3}$, that in order for a new compound (that is, the full-length sequence) to be considered obvious over a related compound (the EST) there must be some motivation to prepare the new compound. Without any information as to the actual biological function of the fulllength sequence, there is no motivation to prepare it from the EST.

On the second point, the author states that the HGS-SB terms for database access are no more onerous than the National Institutes of Health's Uniform Biological Material Transfer Agreement (UBMTA) $^{4}$. The past requirements of HGS for a mandatory exclusive licence to inventions made from the database have apparently been relaxed. HGS now requires "only" an option to negotiate an exclusive licence. This is a recent - and welcome - change brought about in part by public controversy ${ }^{5}$ and the refusal of many academic institutions to accept the earlier terms ${ }^{6}$.

The terms of the new option should not be compared to the UBMTA, however, because the HGS terms apply in cases where only information - not materials is received from HGS. Furthermore, they apply to all inventions produced as a result of the recipient's use of the HGS data/material. The only intellectual property right flowing back to the provider under the UBMTA applies to inventions made by the recipient that are termed "modifications"7. "Modifications" are defined in the UBMTA as materials made by the recipient that physically incorporate the provided material. The recipient is free to patent and license inventions made using the provided materials, even as to modifications, so long as the modifications are not physically transferred to the licensee and the recipient notifies the provider of the filing of the patent application $^{8}$. These patent terms are less burdensome on the recipient university than even the current HGS terms.

On the third point, Merck's efforts ${ }^{9}$ should be applauded. Ultimately, the entire human genome will be sequenced, perhaps as early as 2001 (ref. 10). Hopefully, full-length sequence information will be publicly available, and the present debate will become essentially moot, as has the earlier controversy about patenting genetic markers $^{11}$.

\section{David J. Aston}

University of California,

Office of Technology Transfer,

1320 Harbor Bay Parkway, Suite 150 ,

Alameda,

California 94502, USA

1. Poste, G. Nature 378, 534 (1995).

3. Ex Parte Maizel, 27 USPQ2d 1662 (Bd. Pat. App. \& Int. 1992).

4. Federal Register 60 (45), 12771 (8 March 1995).

5 Dickson, D. Nature 371, 365 \& 463 (1994).

6. Marshall, E. Science 266, 25 \& 1800 (1994).

7. UBMTA, Para. 5(a).

8. UBMTA, Para. 8.

. Dickson, D. Nature 371, 551 (1994).

10. Marshall, E. Science 268, 1270 (1995)

11. Aston, D. Nature 355, 104 (1992).

SIR - Following your recent article about patenting of human genes (Nature 378, $756 ; 1995)$, I should like to clarify the position of Compassion in World Farming (CIWF) on patenting.

CIWF is totally opposed to the patenting of transgenic animals. We fear that the availability of patents will give a huge commercial boost to genetic engineering, a process that poses very considerable threats to the health and welfare of farm animals. The risk of suffering is present both in the laboratory at the development stage and then on farm for the newly 'created' animals.

There is a growing belief that a responsible society should treat animals not as being placed in this world for our convenience but as living creatures capable of feeling pain and suffering. Patenting, involving as it does regarding animals as inventions, as things, is out of step with this modern approach to animals.

If, despite our firm opposition, the proposed European Union directive does eventually sanction the patenting of animals, it is vital that European patent
2. Dickson, D. Nature 374, 751 (1995). law should provide some real protection for the animals involved.

\section{Peter Stevenson}

Compassion in World Farming, Charles House, 5A Charles Street,

Petersfield,

Hampshire GU32 3EH, UK

SIR - I was delighted to see that your first Briefing section contained a full discussion of the implications of the increasing amount of genetic information for the insurance industry (Nature 379, 389-392; 1996). This was one of the concerns discussed in the Science and Technology Committee's report on Human Genetics; The Science and its Consequences (HC (1994-95)41-I).

I fear, however, that you misrepresent the committee in saying that the report supports Dr Nicholas Barr's proposals for spreading risk; as we commented, "such a scheme would need detailed study and design". We did not offer any further opinion on its merits. The significance of the scheme proposed by Barr, and another suggested by Professor Kenneth Arrow, is that they suggest that the problems are not insuperable and that "it would be possible to find ways to regulate the use of genetic information in insurance which would both protect the interests of society in enabling as many people as possible to obtain insurance and protect the insurances companies themselves".

We hope the insurance companies will themselves produce such a solution.

\section{Giles Shaw}

(Chairman, Science and

Technology Committee)

Committee Office,

House of Commons,

London SW1A OAA, UK

\section{Art for science's sake}

SIR - In the discussion about the prevalent distrust of science, it seems to me important that scientists should continue to be open to the influence of art and poetry and other aspects of culture, as they were previously. We don't have to love avant-garde art, but we should show our cultural interests in discussions with students, for example. And poets and other artists should be able to integrate scientific concepts into their art.

I also believe that scientists should be more willing to admit that in spite of their achievements, there is still a great deal to be known about the world around us.

\section{Karl Poralla}

Eberhard-Karls-Universität, Auf der Morgenstelle 1, D-72076 Tübingen,

Germany 